\title{
The Circular Fashion Framework-The Implementation of the Circular Economy by the Fashion Industry
}

\author{
Alessandra Vecchi ${ }^{1,2 *}$ \\ ${ }^{1}$ Department of Management, University of Bologna, Italy \\ ${ }^{2}$ Fashion Business School, University of London Arts, UK
}

Submission: January 27, 2020; Published: February 14, 2020

*Corresponding author: Alessandra Vecchi, Department of Management, University of Bologna, Italy \& Fashion Business School, London College of Fashion, University of London Arts, 20 John Prince's Street N1W 0BJ, London, UK

Keywords: Circular economy; Fashion industry; Business arena; Resources; Materials; Reuse; Repair; Recycling; Eco-Design; Sustainable supply; Socioeconomic opportunity; Designers; Producers; Retailers; Customers

\section{The Implementation of the Circular Economy by the Fashion Industry}

By drawing on the concept of Circular Economy (CE), this paper explores the implementation of the CE by the fashion industry by introducing a Circular Fashion Framework (CFF). The term CE has a long history, multiple definitions, and distinctive developments in different global contexts. In Europe and increasingly worldwide, a CE framework, originally devised and developed in the UK by the Ellen MacArthur Foundation has been a catalyst at policy level and has become a prominent theme in the business arena [1]. A key reason for the widespread popularity of this framework is that it matches a compelling business rationale with the need to decouple wealth creation from the consumption of limited resources. Moving towards a more CE is indeed desirable as it could deliver benefits such as reducing pressure on the environment, improving the security of the supply of raw materials, increasing competitiveness, stimulating innovation, boosting economic growth as well as creating jobs. The fashion industry is the second most-polluting industry after the oil industry and has always been regarded as a creative sector, dynamic and at the forefront of innovation. As such, the industry and its recent dynamics with the advent of new materials, new technologies and new business models is particularly prolific as a source of inspiration and valuable insights into the broader applicability of the CE to other industries.
The rest of the paper is as follows. By drawing on the relevant literature on the $\mathrm{CE}$ the paper develops and introduces a dynamic framework-the CFF - for the application of the CE by fashion firms. By relying on the prior work on the fashion industry [214], the paper provides a detailed description of the framework by outlining some examples as well as the benefits that stem from its application and then offers some concluding remarks.

\section{The Implementation of the Circular Economy}

Since the industrial revolution, we have been living in a linear economy. Our consumer and "single use" lifestyles have made the planet a "take, make, dispose" world. This linear economy model of mass production and mass consumption is testing the physical limits of the globe. It is, therefore, unsustainable and a shift toward a CE is becoming inevitable [15]. Within this context, the $\mathrm{CE}$ is intended as an alternative to a traditional linear economy (make, use, dispose) in which resources are kept in use for as long as possible, while extracting the maximum value from their use and then recovering and regenerating products and materials at the end of each service life [16]. The CE is one that is restorative and regenerative by design and aims to keep products, components, and materials at their highest utility and value always. This new economic model seeks to ultimately decouple global economic development from finite resource consumption. The CE addresses mounting resource-related challenges for business and economies, and could generate 
growth, create jobs and reduce environmental impacts. As the call for a new economic model based on systems-thinking grows louder, an unprecedented favourable alignment of technological and social factors today can enable the transition to the CE. Circular economic activity includes reuse, repair, recycling, eco-design, sustainable supply, and responsible consumption. This profusion of concepts demonstrates that the definition of a circular economy is not set in stone [15]. Nonetheless, a baseline level of understanding can be reached through the available literature. Research by the Ellen MacArthur Foundation focuses on designing with circular economy principles from the beginning, in the ideation phase [1].

While their work offers much in the way of creating a CE, it could do more on pathways for firms to transition a linear economy production line to a circular economy model. To enable firms and institutions to develop a model that allows for leveraging the use of underutilized resources, [17] propose a three-phase model development guideline that uses three key drivers-resource constraints, technological development, and socioeconomic opportunity-to create regenerative business models by design that involve the creation of a new breed of services that leverage long-term use and maintenance. They conclude that by following such an approach, business models will be based on reincarnation and efficiencies in product design, systems design, and the use of new materials. Esposito and colleagues [15] further claim that adopting the CE model requires that firms initiate and develop disruptive technology and business models that are based on longevity, renewability, reuse, repair, upgrade, refurbishment, servitization, capacity sharing, and dematerialization. Noting that firms often struggle to change their existing linear business models to circular models, [18] have proposed a roadmap for circular business model transformation. The pace at which companies are adopting the CE has been accelerating for the last two decades and it has evolved from a specialist concept to a mainstream business strategy.

\section{The Implementation of the Circular Economy in the Fashion Industry}

In a circular fashion industry, all the stakeholders, namely designers, producers, retailers and customers are all challenged to take the whole life cycle of a garment into account. More specifically, in the CFF we can identify six phases as depicted in the Figure 1 below.

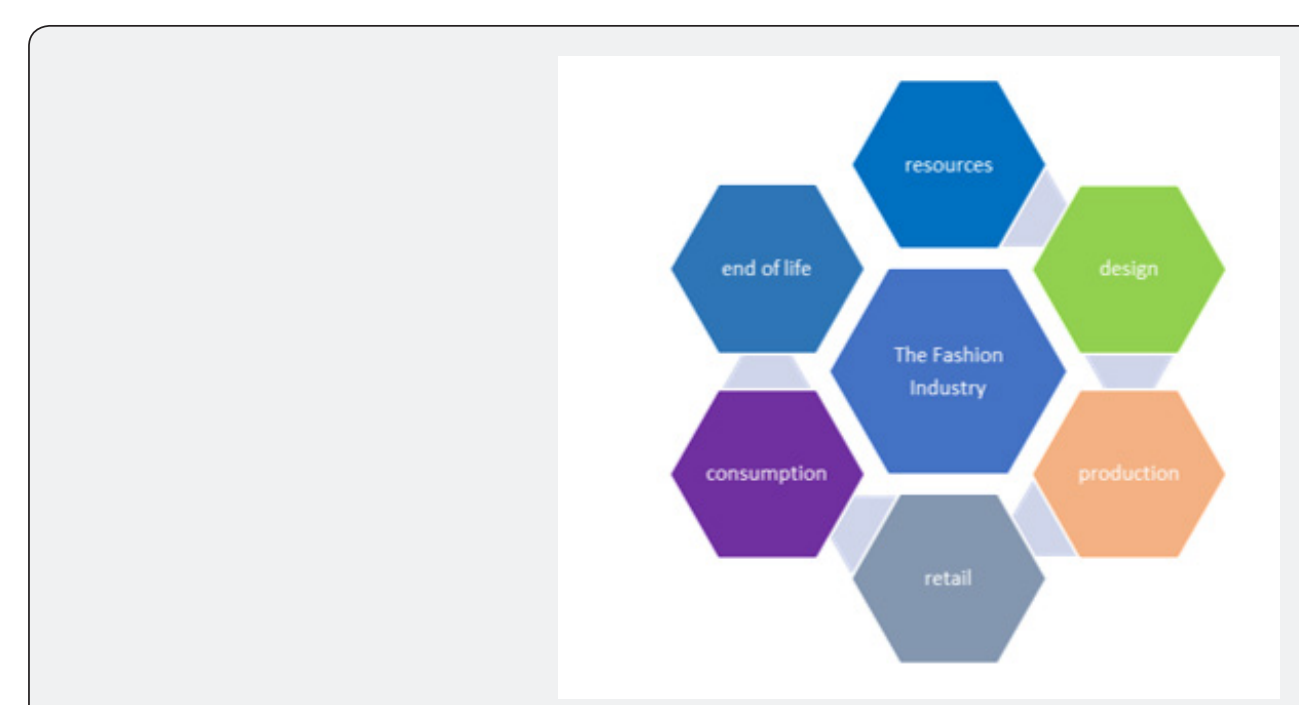

Figure 1: The Circular Fashion Framework.

\section{Resources}

Deciding which fabric to use is one of the most crucial aspects of the design process, affecting not only the esthetics of a garment, but also its lifespan and quality, as well as its environmental impact. Manufacturers need to carefully assess what is the impact of the materials they use and to identify which resources are environmentally friendlier than others. Additionally, it is important to consider the end of the product's life from the very outset to assess whether there are options to re-use clothes after their use, options for recycling them, identify those resources that are easiest to reuse at the end. Manufacturers need to take into account the consequences of using certain coatings, accessories and finishing's since these are likely to have a significant impact on the recycling process. Manufacturers might want to consider experimenting with nontraditional textiles, like fabric made from biowaste such as fabric made from PET bottles, such as the Repreve yarn that is used to make everything from jackets and T-shirts to dress pants and even car upholstery. It is used by brands like Patagonia, The North Face, Levi's, Adidas and Nike. 


\section{Design}

Decisions made during the design phase are responsible for 80 to $90 \%$ of the environmental and economic costs. In contemporary society, 'planned obsolescence' has become an important strategy to ensure an ever-growing rate of consumption. Fashion designers are not only responsible for the choice of materials, styles, colors and shapes. The design approach that they adopt should take into account the entire life cycle of the product. Every individual step is important, from resources to design, production, retail, consumption and end of life. Long-lasting design as used by well-known companies such as Esprit and Filippa $\mathrm{K}$ that outlive trends and hypes and high quality should be of paramount importance. Otherwise if a product does not last long, design for rebirth by contemplating every possibility in terms of re-use, repair, redesign and recycling could be another option. In any case, the golden rule of circular design is to avoid waste or surplus as much as possible by implementing a design that minimizes waste through smart production solutions, or by reusing of someone else's waste (as for Wrad that uses graphite recycled from hi-tech production to produce t-shirts) or by implementing multifunctional designs (from Louis Vuitton to Roger Vivier, multifunctional items are proliferating). Additionally, in order to avoid both fast consumption and overconsumption, the designer can also devote attention to the experience and the involvement of the customer, by thus ultimately strengthening the relationship between the user and the product. This includes service models, as well as interactive/cooperative design, customization, timeless aesthetics and emotional design. Similarly, it is important to design by adopting those techniques that tend to generate relatively less waste than some that are more currently used such as knitting, 3D printing and 3D weaving to name a few.

\section{Production}

In a traditional process, the design phase is followed by the creation of a small sample collection. Those prototypes that are deemed as suitable will enter production. This means switching to commercial entities varying in size, color and pattern. During this phase, it is important to incorporate zero waste thinking into the production of prototypes, for instance by creating the sample collection digitally (as done by Hugo Boss) or by working with zero waste pattern designs (as done by Issey Miyake). When selecting a production process, it becomes an imperative to take into account energy and water consumption, to comply with the environmental legislation and to minimize the use of chemicals. The core of a sustainable product lies in its quality and its durability, so the importance of quality control during the production phase should not be overestimated. Producing locally obviously facilitates both quality control and the implementation of corrective measures. In addition, it reduces the wide range risks that are traditionally associated with a global supply chain, especially for smaller collections. In addition, looking beyond the standard methods of production by including digital technologies, for instance, such as digital design, digital printing or 3D weaving allow for small collections or production on demand. The latter in particular allows for customization, by thus establishing a stronger bond with the consumer who is more likely to develop emotional attachment toward a customized product by ultimately curbing overconsumption, surplus and overproduction.

\section{Retail}

Retailers have also a significant contribution to make in the implementation of the CE. Establishing a take-back model, the possibility to return garments to the retailer, who gives clothes a second life as resources for new items, is gaining popularity. This is often the case when the manufacturer is also the retailer as in the case of Eileen Fisher. The company collected 220,000 items of used clothing in 2018, with take-backs having risen by an average of $15 \%$ year-on-year. Clothing in pristine condition (about 60 per cent of collections) is cleaned and resold under the Renew brand, while lightly damaged pieces are upcycled into new pieces. A second option is gaining momentum within the sharing economy, where customers tend to pay for renting clothes rather than owning them (e.g. Drexcode, Rent the Runaway, Le Tote). There are plenty of online possibilities to give clothes a second life. Many platforms allow customers to sell (e.g. Depop, Vestiaire Collective) or swap their clothes peer-to-peer (e.g. Rehash Clothes, Swap). Furthermore, today's customers attach more and more importance to the experience. Focusing on these aspects as a retailer will enhance the bond with the customer and create ambassadors for the brand. Small services such as repairing services, styling advice, made-to-measure clothing and personalization (e.g. Flair Atelier) will further strengthen the bond. As for the impact of the brand's marketing efforts, hangers, tote bags, and price tags are also likely to make a significant difference.

\section{Consumption}

Customers play a big role too. In all sectors, customers are becoming more conscious and more outspoken, asking questions about labels, resources, production, transparency and traceability (e.g. Fashion Revolution Network's Campaign "\#whomademyclothes"). Retailers and manufacturers should be able to provide adequate answers to these questions. Customers are increasingly explore the possibilities beyond fast fashion, such as swishing, swapping, second-hand stores and online platforms. In terms of clothes maintenance, customers can contribute significantly by buying less and by taking good care of their clothes to extend their durability. Similarly, customers are increasingly interested in repairing and engaging in DIY, as seen in the rise of sewing and knitting workshops, which cater to people who want to make, repair or upcycle their own clothes. Furthermore, customers increasingly want to donate clothes with the purpose of recycling, upcycling or giving clothes a new 
life.

\section{End-of-life}

$20 \%$ of global production waste comes from the textile and apparel sectors. There are many ways in which this percentage can be reduced. This requires the orchestrated effort of manufacturers/retailers and customers. Manufacturers should use biodegradable fabrics, engage in circular design and production processes that are fit to the purpose. Reusing fabrics for new designs is relatively simple as well as reuse fibers whenever it is possible. Customers should upcycle their clothes, while returning the clothes that are no longer wanted. Re-using is also the most sustainable option of all to prolong life.

\section{The Impact of the Circular Fashion Framework}

While the traditional implementation of the CE is often "skin deep" [19] - mostly driven by a reactive approach whereby companies seek to comply with the CE implementation as it would for any other market requirements, the fashion companies have the potential to show a radically different vision by endorsing a much more proactive approach which can "flash deep" that might ultimately yield many tangible benefits that are all well-beyond mere cost-savings stemming from recycling and reuse. Many of the existing fashion companies who are engaging with the CFF are establishing themselves with a CE based business model from their outset. Remarkably, they are not attempting to implement it into an already existing business model. Nonetheless, the implementation of the CE "flash deep" as in the case of the CFF could provide many benefits also to incumbent firms. In particular, the managerial implications are manifold. Just as fashion actors have benefited from extending beyond their core activities, there are opportunities for managers in other sectors to do like likewise developing additional revenue streams via servitization. The embrace of the CE has the potential to deliver signifiicant returns whether in terms of cost reduction, the development of a self-sustaining organisational innovation and creativity engine, the opening up of possibilities for new ventures and the establishment of new disruptive business models that drive sustainable competitive advantage. However, if the organisation's embrace of the CE is to realise its potential, managers need to pursue an entrepreneurial vision that is holistic in nature and that calls for the setting and pursuit of ambitious goals. Success from embracing the CE calls for managers to encourage and nurture a mindset and practice that is open to intensive experimentation that includes multiple trial and error iterations and that is infused with action learning.

In turn, this demands a high degree of resilience within the organisation. Equally well, an entrepreneurial mindset can sustain the efforts around experimentation but also contribute the capacity to envisage and forge possibilities for new ventures and innovative business models. As the current experiences in the fashion industry indicate, embedding learning via experimentation, action learning cycles, resilience and an entrepreneurial mindset is the critical point of departure if the potential successes and benefits of the CE are to be attained. Ensuring this, calls for effective leadership that combines holistic vision, ambition and resilience.

Overall the fashion industry demonstrates the benefits and the advantages that can accrue from embracing the CE. Our analysis reveals that fashion companies develop organizational capabilities that can produce significant cross-savings as well as unleashing creativity and innovation. Furthermore, embracing the CE can yield new business models that drive sustainable competitive advantage. These new business models include those characterised by circular supplies, replacing single life-cycle inputs, resource recovery where resources are recovered from disposed products and product life extensions. Consistent with the findings of the recent [19] Accenture Strategy study (2019) that reports that first-movers have a holistic vision coupled with effective leadership, we observe similar characteristics among the first-movers in the fashion industry. The insights provided by the fashion industry provide valuable lessons that can have broader applicability to all firms from all the other sectors but particularly to those that similarly to the fashion industry are creative sectors, rely on R\&D and are knowledge-intensive and that are exposed to fierce competition.

\section{References}

1. Ellen MacArthur Foundation (2013). Towards the Circular Economy Vol. 2: Opportunities for the consumer goods sector, UK, pp. 1-112.

2. Black S, Williams D, Burcikova M, Vecchi A, Norton Z, et al. (2019) Study on Mapping Sustainable Fashion Opportunities for SMES. pp. 1-21.

3. Della Piana B, Vecchi A (2017) The Internationalization of a Family Business Group: The ownership, the leadership and the importance of the socio-emotional wealth dimensions. Italian Fashion Industry 15(4): 380-404.

4. Kontu H, Vecchi A (2013) From Laggards to Leaders? The Strategic Use of Social Media in the Fashion Industry. In: Christiansen B, Williams N, Turkina E (Eds.), Published in Transcultural Marketing for Incremental and Radical Innovation, IGI Global, USA, pp. 1-46.

5. Kontu H, Vecchi A (2014) Why all that noise? Assessing the strategic value of social Media for fashion brands. Journal of Global Fashion Marketing 5(3): 236-251.

6. Kontu H, Vecchi A (2016) Fashion and Social Media: Some Illustrative Evidence from Italian Luxury Brands. Handbook of Research on Global Fashion Management and Merchandising. In: Vecchi A, Buckley C (Eds.), IGI Global, USA, pp. 1-32.

7. Peng F, Vecchi A, Al-Sayegh M, Hamilton S (2016) How to Use Sizing Technology and Fashion Metadata to Improve the User Experience for Online Fashion Retail. Handbook of Research on Global Fashion Management and Merchandising. In: Vecchi A, Buckley C (Eds.), IGI Global, USA, pp. 261-279.

8. Vallisi V, Vecchi A (2016) Benetton's response to the Increasing global competition. Handbook of Research on Global Fashion Management and Merchandising. In: Vecchi A, Buckley C (Eds.), IGI Global, USA, pp. $1-20$.

9. Vecchi A, Buckley C (2016) Handbook of Research on Global Fashion Management and Merchandising. In: IGI Global, USA, pp. 1-862.

10. Vecchi A (2008) Globalisation and the Viability of Industrial Districts. 
In: Germany, pp. 1-376.

11. Vecchi A (2017) Advanced Fashion Technology and Operations Management. (Ed.) IGI Global, Hershey, Pennsylvania, USA.

12. Vecchi A, Peng F, Al-Sayegh M (2014) Assessing the applicability of a sizing framework into online fashion retail. International Journal of Advanced Information Science and Technology 3(9): 1-9.

13. Vecchi A, Peng F, Al-Sayegh M, Hamilton S (2016) Enhancing online fashion retail - the quest for the perfect fit. In: Machado C, Paulo Davim J (Eds.), Technological Challenges \& Management: Matching Human \& Business Needs. CRC Press - Taylor and Francis Group, USA.

14. Vecchi A, Peng F, Al-Sayegh M (2017) Size Recommendations in Online Fashion Retail-Opportunities and Challenges. Advanced Fashion Technology and Operations Management. In: Vecchi A (Ed.), IGI Global, USA, pp. 1-15.

15. Esposito M, Tse T, Soufani K (2018) Introducing a Circular Economy:
New Thinking with New Managerial and Policy Implications. California Management Review 60(3): 5-19.

16. Hopkinson P, Zils M, Hawkins P, Roper S (2018) Managing a Complex Global Circular Economy Business Model: Opportunities and Challenges. California Management Review 60(3): 71-94.

17. Lacy P, Rutqvist J (2015) Waste to Wealth: The Circular Economy Advantage. (1 ${ }^{\text {st }}$ edn), New York, pp. 1-8.

18. Frishammer J, Parida V (2019) Circular Business Model Transformation: A Roadmap for Incumbent Firms. California Management Review 61(2): 5-29.

19. Sudipta Ghosh, Kevin Eckerle, Harry Morrison (2019) Accenture Strategy. Full Circle. Turning Waste into Value with your Supply Chain. pp. 1-13.

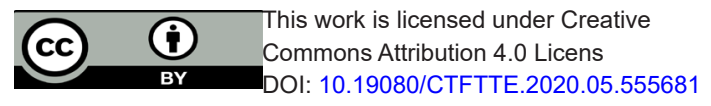

\section{Your next submission with Juniper Publishers will reach you the below assets}

- Quality Editorial service

- Swift Peer Review

- Reprints availability

- E-prints Service

- Manuscript Podcast for convenient understanding

- Global attainment for your research

- Manuscript accessibility in different formats ( Pdf, E-pub, Full Text, Audio)

- Unceasing customer service

Track the below URL for one-step submission https://juniperpublishers.com/online-submission.php 